\title{
El asentimiento religioso en John Henry Newman*
}

\section{Patricio Merino Beas**}

Recibido: 15 enero de 2013 • Aprobado: 25 de marzo de 2013

\section{Resumen}

Este sencillo artículo quiere ser un homenaje al Beato J. H. Newman, al cumplirse tres años de su beatificación. Para ello, junto con una breve semblanza de su bio-bilbliografía se presentan las categorías clave de una de sus obras principales: "Essay in aid of a grammar of assent (1870)". Puesto que ésta representa una contribución importantísima para la larga tradición católica en su comprensión del diálogo entre fe y razón.

Palabras clave: Newman, asentimiento religioso, diálogo fe y razón.

\section{Religious assent in John Henry Newman}

\begin{abstract}
This simple article is a tribute to Blessed J. H. Newman, in the third anniversary of his beatification. Therefore, along with a brief profile of his biobibliography we present key categories of one of his main works: "Essay in aid of a grammar of assent (1870)". Since it represents a major contribution to the long catholic tradition in its understanding of dialogue between faith and reason.

Keywords: Newman, religious assent, dialogue faith and reason

* Artículo resultado de la investigación del autor.

** Doctor en Teología por la Universidad Pontifica de Salamanca, profesor de la Universidad Católica de la Santísima Concepción, Chile. Correo electrónico: pmerino@ucsc.cl
\end{abstract}




\section{A modo de introducción: algunos datos importantes sobre la vida de J. H. Newman}

John Henry Newman nació el 21 de febrero de 1801 en Londres. Fue el mayor de seis hermanos, su padre era banquero y su madre descendía de refugiados hugonotes. Su familia lo educó en sus primeros años con criterios religiosos de corte más bien liberal. Como él relata, a los quince años tuvo su primera conversión (otoño de 1816) influenciada sobre todo por ideas calvinistas que le "proporcionaron las certezas" que hasta entonces no tenía.

En octubre de 1817 ingresó en el Trinity College de Oxford. Allí obtuvo su bachillerato en artes y recibió el influjo más fuerte del liberalismo religioso. Continuó sus estudios y en 1824 fue ordenado diácono y nombrado coadjutor de la Parroquia de San Clemente en Oxford, en 1825 fue ordenado Presbítero de la Iglesia Anglicana. Más tarde siendo párroco en Santa María de Oxford entró en contacto con los miembros del movimiento de tendencia anglo-católica que se cristalizó en lo se llamó movimiento de Oxford o Tractariano (1833-1839).

Este movimiento estaba conformado por un grupo de hombres cuya causa común era luchar contra el peligro que amenazaba a la fe Anglicana, demasiado influida por el liberalismo y el intelectualismo. Sin embargo, el principal detonante de este movimiento fue la ley de reforma política de 1832 con la cual la Iglesia quedaba sometida al Parlamento y perdía su libertad.

Vale la pena recordar los principios que sustentaron al movimiento de Oxford:

- La defensa del dogma, frente a la negación liberalista.

- La visibilidad de la Iglesia, manifestada en los sacramentos y ritos como canales de la gracia invisible.

- $\quad$ El principio anti-romano.

- El estudio de la patrística y de las fuentes cristianas, como recuperación de los orígenes que fundamentan la fe.

- Una concepción de la catolicidad de la Iglesia consistente en tres ramas: La anglicana, la griega y la romana, en la que cada una es realmente la Iglesia Católica sobre el territorio que ocupa.

- La "vía media", que consistía en una línea intermedia entre el protestantismo y el catolicismo romano, manteniendo contra el primero la autoridad de la tradición, especialmente la de los padres de la Iglesia 
$\mathrm{y}$, frente al segundo, rechazando las que le parecían innovaciones al Evangelio o "añadidos romanos".

También por esa época publicó su libro “Los arrianos del siglo IV” (1833), obra importante, porque le permitió entrar en contacto con la Iglesia primitiva y las fuentes de la revelación. Sus estudios sobre los primeros siglos de la Iglesia, en concreto sobre los monofisitas y los arrianos, le abrieron a hacer comparaciones entre los protestantes, los anglicanos y los católicos romanos, pareciéndole que la Iglesia del siglo IV reflejaba la realidad de la Iglesia de hoy. De este modo: los arrianos serían los protestantes, los semiarrianos corresponderían a los anglicanos y la Iglesia romana, a su juicio, permanecería tal cual. Estas apreciaciones le trajeron varias dificultades dentro de su Iglesia. Luego de un proceso personal, se convirtió a la Iglesia Católica romana y es recibido en la plena comunión católica en Littlemore por el padre Domingo Barberi el 9 de octubre de 1845.

$\mathrm{Al}$ año siguiente se trasladó a Roma para estudiar teología en el colegio de Propaganda fide. En 1847 es ordenado sacerdote y comienza el noviciado en el Oratorio de San Felipe Neri.

En 1851 se le encargó dirigir la Universidad Católica en Dublín, proyecto que fracasó a causa de la falta de libertad y la necesidad de su presencia en el Oratorio de Birmingham que había creado antes. Sin embargo, alcanzó a escribir su "The idea of a University" (1852), que ha ejercido mucha influencia en el ámbito universitario católico.

Años más tarde dirigió la revista "The Rambler", desde la que hizo una gran labor de defensa del papel del Laicado y del "sensus fidelium" como lugar teológico.

Otras de sus obras destacadas son la "Apología pro vita sua" (1864) en la que cuenta su proceso de conversión y el desarrollo de sus ideas religiosas y el célebre "Ensayo sobre el desarrollo de la doctrina cristiana" (1845), además de sus "Sermones Universitarios" (1826-1843, pronunciados en Oxford antes de su conversión al catolicismo).

En 1879 fue nombrado Cardenal por León XIII. Murió el 11 de agosto de 1890. Y fue beatificado el 19 de septiembre de $2010^{1}$.

1 Se puede leer la Homilía de Benedicto XVI con motivo de su beatificación en: http://www.vatican.va/holy_father/benedict_xvi/homilies/2010/documents/hf_ben-xvi_ hom_20100919_beatif-newman_sp.html (citado el 7 de abril de 2014). 


\section{Notas sobre la aportación teológica de Newman}

Aunque este artículo se centrá en su libro: Essay in aid of a grammar of assent (1870), antes nos referiremos brevemente a dos de los aportes más reconocidos de su extenso trabajo intelectual: el desarrollo del dogma y la relación entre fe y razón ${ }^{2}$. En el cuerpo del texto, haremos referencia a un tercero: el lugar que ocupa la conciencia y la manifestación de Dios en ella.

\subsection{El desarrollo histórico del dogma}

La participación de Newman en el movimiento de Oxford, con su ya señalado énfasis en la investigación de los orígenes de la Iglesia primitiva y el estudio de los Santos Padres, le permitieron, en un primer momento, proponer la denominada "vía media" como solución al problema de la relación entre revelación-tradiciónautoridad, sobre todo basado en el criterio de antigüedad. Esta vía media consistía en considerar al anglicanismo como punto de equilibrio entre el pensamiento católico romano, que según la visión anglicana corrompía la pureza original de la Iglesia primitiva añadiendo nuevos dogmas, y aquel protestantismo que negaba toda tradición dogmática y de autoridad. No obstante, la dirección que fue cobrando su investigación y su honestidad intelectual, lo llevaron a mirar con nuevos ojos la evolución de la doctrina y su interpretación, considerando dicha evolución más bien como un elemento constitutivo de la concreción histórica de la revelación que se desarrolla en la tradición y, cuya autenticidad, tiene su base en la autoridad apostólica de la Iglesia, continuada por la sucesión apostólica y el episcopado. Es decir, llega a plantear que existe una continuidad histórica entre la enseñanza apostólica y el cuerpo de doctrinas expresadas y concretadas por la fe católica a lo largo de los siglos.

2 Para este punto se sigue principalmente a torRes QuirogA, .A, “John Henry Newman: Fe y Razón en una época de crisis", Revista Española de Teología 51 (1991) 5-42. También, González Montes, A., "Trayectoria teológica de Newman. Hacia la Iglesia Católica. Aproximación biográfica y tarea ecuménica", Diálogo Ecuménico 86 (1991) 61-78; Jiménez orTIz, A., "de la apologética clásica a la teología fundamental. La presencia de John Henry Newman", Diálogo Ecuménico 86 (1991) 183-202; PELÀ, G., "Newman y el desarrollo de la teología que inspiró al Vaticano II", Diálogo Ecuménico 86 (1991) 171-182. 


\subsection{La relación entre la fe y la razón}

Este tema es transversal a toda la obra que analizaremos. Por ello, es suficiente aquí dejar constancia de cómo Newman es capaz de sortear dos extremos siempre amenazantes del quehacer teológico y de la vida del cristiano. Por una parte, la reducción racionalista y empirista que no deja cabida a la fe y, por otra parte, el fideísmo que desacredita el papel de la razón. De la misma manera, su reflexión permite vivir una vida religiosa que trasciende todo relativismo y dogmatismo estático o frío. Newman reconoce las posibilidades de la razón, pero basa la razonabilidad de la fe en una certeza fundada en la autoridad divina. También propicia una fe no puramente noética y abstracta, sino vital y real que integra al hombre entero.

\section{3. "El Asentimiento Religioso" (Newman, 1960)}

El "Asentimiento religioso" ${ }^{3}$ es una obra que no viene exigida por causas concretas, más bien tiene la finalidad de exponer sus apreciaciones sobre ciertos problemas que le habían preocupado por años. Su tesis principal es que la filosofía de corte racionalista, que reinaba en su contexto, no era capaz de explicar y abordar de manera adecuada todos los hechos de nuestra existencia y menos el de la experiencia religiosa. Para él unos métodos estrictamente racionales (reduccionistas) dejan sin explicación satisfactoria una serie de hechos de cuya legitimidad y realidad es absurdo dudar.

Su preocupación se puede formular a través de una pregunta: ¿Cómo creer lo que no puede demostrarse (según la restrictiva racionalidad empírico-matemática)? (Cabrera, 2010).

La originalidad de su respuesta radica en que su punto de partida será su experiencia religiosa y no proposiciones deductivas y demostrables por principios generales, dicha experiencia religiosa sería portadora de una racionalidad que le es propia, a la cual no corresponde una racionalidad lógico-discursiva que sólo llevaría a un conocimiento nocional de Dios y su revelación.

Newman propone una racionalidad que lleve a un conocimiento real, de modo tal, que sea posible alcanzar una certeza que comprometa al sujeto entero, en sus afectos, pensamientos y acciones. Aplicado a la fe, su preocupación de

3 Desde este punto se identifica Asentimiento Religioso con la sigla "AR". 
fondo es dar fundamento a la certeza religiosa necesaria para sostener una vivencia comprometida ella o, dicho de otra manera, cómo lograr un asentimiento no solo nocional, sino verdadero de la realidad de Dios. Es decir, se pregunta por la razonabilidad de la fe.

El contexto de la obra de Newman está dado principalmente por el espíritu racionalista ${ }^{4}$-empirista que reinaba en Inglaterra y en la Universidad de Oxford. Se exigía una prueba científica, absolutamente comprobable, rigurosamente lógica de todo lo que el hombre creía. Se consolidaba en Oxford un sistema educativo que reducía todo conocimiento al modelo de la racionalidad matemática y silogística. A lo que más tarde se agregó el método inductivo y experimental. Frente a esto, Newman considera que no es posible reducir la racionabilidad de la fe a los métodos racionalistas y empiristas. El a $A R$ no sigue una lógica estricta ni intelectualmente reductiva, sino que involucra a todo el hombre, es decir, su imaginación, sentimientos, memoria, etc. Pero tampoco concibe Newman fundar la certeza cristiana en un puro sentimentalismo.

El espíritu racionalista influyó en la manera de concebir la fe cristiana por parte de muchos grupos religiosos cristianos de la época, quienes fueron decayendo en un deísmo configurado en un protestantismo de corte liberal ${ }^{5}$. Este liberalismo, ante todo, menospreciaba o negaba toda posibilidad de revelación sobrenatural y, por tanto, de desarrollo y autoridad dogmática vinculante de la fe. Frente a esto, Newman se destacó por su esfuerzo anti-liberal (en su sentido antidogmático), frente al cual realizó una consistente defensa de la posibilidad de la revelación y la continuidad del dogma. Para él, la fe y el $A R$ no tienen su fundamento último en la fuerza de la razón y, por tanto, no puede ser reducida a demostración o prueba, estrictamente hablando. Este constituye, justamente, el problema y la piedra de tope para quienes reducen toda certeza a las conclusiones

4 Así se expresa Newman sobre el racionalismo en: Essay Critical and Historical, I, 31: "El racionalismo es un cierto abuso de la razón, ... un uso de ésta para propósitos para los que nunca fue pensada, y es hacer de nuestra razón el modelo y la medida de las doctrinas reveladas... Así, un espíritu racionalista es el antagonista de la fe; pues la fe es, en su misma naturaleza, la aceptación de lo que nuestra razón no puede alcanzar, simple y absolutamente en base al testimonio". Citado por Francisco Cabrero, o. c., 23.

5 Sobre el liberalismo en su Apología pro vita sua, 254, dice: “... Por liberalismo entiendo una falsa libertad de pensamiento, o el ejercicio del pensamiento sobre materias en las cuales, a causa de la constitución de la mente humana, el pensamiento no puede ser llevado a ninguna conclusión fructuosa, y por tanto, está fuera de lugar" y También, "El liberalismo es, entonces, el error de sujetar al juicio humano aquellas doctrinas reveladas que, por su naturaleza, son independientes y están más allá de aquél; y de reclamar la determinación sobre fundamentos intrínsecos de la verdad y el valor de proposiciones, cuya recepción se basa simplemente en la autoridad externa de la Palabra de Dios". 
de una ciencia exclusivamente lógica y empírica (reduccionista). Para quienes así piensan no hay lugar para el misterio, para lo sobrenatural, para el credo como fórmula objetiva y para la Biblia como texto revelado.

El racionalismo y liberalismo imperante en Inglaterra fue haciendo que la fe se enfriara, que la idea de Dios se difuminara y la religiosidad se volviera abstracta y cada vez más carente de contenido ${ }^{6}$ o bien que, simplemente, ésta cayera en el extremo contrario de un fideísmo y fundamentalismo.

\subsection{Argumento de la obra y conceptos clave?:}

El $A R$ es un ensayo que busca fundamentar la razonabilidad de la fe y la certeza que puede alcanzar el cristiano sobre las verdades centrales de su fe. Es pues un ensayo apologético, pero no apologista o polémico, se trata de dar razón de la fe, de testimoniarla. Pretende mostrar que el cristiano obra razonablemente al prestar su pleno asentimiento a las verdades religiosas, aunque no pueda presentar en su apoyo pruebas estrictamente irrefutables desde el punto de un racionalismo restrictivo. Por lo tanto, no pretende convertir a los incrédulos, sino argumentar que los cristianos menos instruidos y con poco conocimiento sobre las razones en que se apoya su fe, obran, sin embargo, razonablemente al abrazarla sin condiciones.

Con este fin, distingue entre aprehensión y asentimiento, entre asentimiento e inferencia, mostrando que la fe religiosa es un asentimiento más que una inferencia. El asentimiento sería la aceptación absoluta e incondicional de una proposición, mientras que la inferencia sería una aceptación condicionada a la verdad y realidad de las premisas. De ordinario, un asentimiento va precedido por una inferencia, pero esto no es siempre así ni necesario. Por tanto, asentir no es inferir ni viceversa. De esto concluye Newman que la fe no necesariamente está en función de razones inferenciales que puedan aducirse a favor de ella. Pudiera ser que alguien viera razones suficientes y que, sin embargo, no dé su asentimiento. No obstante, el acto de fe será más perfecto en el orden racional cuanto más explícitos estén en la mente del creyente los motivos racionales en que funda su acto de fe.

6 Por ejemplo escribe: “... nuestra religión nacional profesa ser poco más que leer la Biblia y vivir una vida correcta. No es una religión de personas y cosas, de actos de fe y de devoción directa sino de escenas sagradas y de sentimientos piadosos. Relativamente ha descuidado el credo y el catecismo", en: El Asentimiento religioso, o. c., 33.

7 Se sigue sobre todo la introducción a la edición Española de la editorial Herder, o.c. Y a Rino Fisichella en: “Newman”, Diccionario de Teología Fundamental (Madrid 1992) 1024-1029. 
De ahí que la racionalidad no constituye en sí misma la perfección del acto de fe, sino que ésta radica en la libertad con que el sujeto da su asentimiento.

Además, distingue entre un asentimiento nocional y uno real. Por asentimiento nocional entiende aquél que se da a proposiciones cuyos términos representan nociones e ideas. Mientras que el real tiene por objeto proposiciones cuyos términos representan cosas concretas. Para Newman, el asentimiento real tiene más fuerza que el nocional, porque su fuerza, más que basarse en cualidades lógicas se basa en cualidades psicológicas, queriendo decir con esto que es todo el hombre el que asiente.

¿Qué es lo que distingue, pues, al asentimiento nocional del real? El real lleva a la acción y penetra toda la vida de un hombre, pudiendo conducirlo hasta las cumbres del heroísmo; el nocional se queda en la región de la teoría e influye poco en la vida del que lo posee. En el proceso de aprehensión de una proposición, tiene una gran función la imaginación, ya que sus imágenes impresionan y afectan los sentimientos, tales como, la esperanza, el temor, los gustos, las repugnancias, los apetitos, las pasiones, la agitación, el egoísmo, el amor, etc., ya que son estos los que en realidad mueven a la acción. El asentimiento real consiste en un asentimiento que, de alguna manera, afecta e implica a la imaginación y al asentimiento moviendo a la acción. Por ello, Newman no duda en afirmar que el asentimiento que exige el cristianismo es el real, porque compromete no solo a la inteligencia, sino a todo el hombre.

El asentimiento religioso ha de ser un asentimiento real, pero para que tal asentimiento sea racional ha de prestarse a un objeto verdadero. La dificultad está en que el asentimiento en sí no nos da la garantía de la verdad de su objeto. Hay asentimientos que no son más que supersticiones, caprichos o fanatismos. Sin embargo, el asentimiento racional exige una garantía de verdad, De este modo, el problema del asentimiento de fe es que no tiene una evidencia inmediata, directa o irrefutable.

Ante los ataques del racionalismo exacerbado, Newman afirma que el asentimiento religioso, para ser racional, ha de fundarse en una verdadera certeza de la verdad de su objeto; pero que, no obstante, esta verdad puede constar por caminos diversos de los que proporciona la prueba estrictamente racional de tipo matemático o logístico.

¿Cómo llegar a esta certeza en que se basa el acto de fe? El camino es el asentimiento que pasa por la inferencia, pero no entendida como de ordinario suele hacerse; es decir, como producto de un razonamiento estrictamente lógicoformal, sino como uno que se basa en probabilidades convergentes. Por medio de una lógica formal basada en los símbolos lógicos, como por ejemplo, el lenguaje y 
la matemática, solo se alcanza un conocimiento nocional que limita en su expresión la complejidad y riqueza de la realidad. La lógica formal o verbal es incapaz de proporcionar adecuado fundamento al asentimiento real. Así en el plano religioso, la inferencia formal, por ejemplo aplicada a la existencia de Dios, a lo sumo permite dar un asentimiento nocional de su existencia, pero no real. De ahí que se esfuerce en establecer que toda religión se basa en un asentimiento más bien existencial y que la garantía de verdad de tal asentimiento está en el testimonio constante de nuestra conciencia que nos coloca inmediatamente frente a Dios, entendido aquí bajo la imagen de legislador y juez de nuestras acciones. Para él es un hecho significativo que en la historia de las religiones y en la psicología humana, se muestre que el hombre sentirá remordimiento al hacer ciertas acciones aunque no sepa nada de la existencia de un ser remunerador. En este mismo sentido es frecuente ver en todas las religiones ritos de expiación.

Habría que tener en cuenta que este argumento de la conciencia es sólo uno más de las probabilidades convergentes de la existencia de Dios. Hay detalles insignificantes que en su conjunto pueden mover a un hombre más que todos los argumentos lógicos e irrefutables. Nuestra vida está hecha de actos de fe. La racionalidad de las creencias está garantizada por la existencia de un número infinito de razones, que aunque cada una por sí misma no sea mas que una tenue posibilidad, sin embargo, su convergencia unánime en apoyo de una cosa basta para crear una certeza racional sobre la misma. Ahora bien, este paso de probabilidades a certeza, más que por un silogismo lógico, se hace por lo que Newman llama el "sentido ilativo".

El asentimiento que damos a la lógica no formal de las probabilidades convergentes, no es menos racional que el que damos a la lógica formal de la demostración estricta. Los métodos de prueba dependen de la naturaleza del objeto que ha de probarse y es irracional pretender probar una cosa por un método que no se le adapta. Todo cristiano, aunque no se haya dedicado a la lógica o a la metafísica, puede prestar un asentimiento racional a las verdades religiosas, puesto que puede tener un número suficiente de probabilidades convergentes a favor de su creencia. Las verdades fundamentales del cristianismo responden a esta forma de asentimiento. Newman enumera por ejemplo: la gran serie de probabilidades antecedentes que tienden a establecer la verdad de la religión natural. Las sugerencias repetidas de la conciencia, el orden maravilloso del mundo externo, las providencias admirables que se descubren en los sucesos de la vida de los hombres. Vienen luego las numerosas probabilidades de orden histórico y moral a favor de la verdad del cristianismo como religión revelada; el cumplimiento de los vaticinios antiguos, los milagros, las pruebas de autenticidad y veracidad de 
los evangelios, la renovación moral obrada por el cristianismo en el mundo pagano, su maravillosa difusión, el heroísmo de los mártires, etc. Todas en su conjunto permiten dar un asentimiento racional de tipo real a la existencia de Dios y a las proposiciones cristianas, dice Newman.

\subsection{Desarrollo de los conceptos claves de la obra}

\subsubsection{Aprehensión y asentimiento}

Los primeros conceptos que distingue Newman en su $A R$ son la aprehensión y el asentimiento.

Por aprehensión entiende "la interpretación que damos a los términos que componen una proposición" (Newman, 1960), es decir, aprehender una proposición dada requiere dar sentido a los términos que forman parte de ella. Por tanto, hay una fuerte implicación del sujeto que aprehende y que más adelante permitirá explicar, porque hay sujetos que frente a una proposición dada la entienden en sentido nocional y otros en sentido real. Ahora bien, hay aprehensiones que se refieren a conceptos y proposiciones abstractas, generales o inexistentes en forma real, a estas las llama aprehensión de tipo nocional, porque aprehende proposiciones nocionales (Newman, 1960). En cambio, cuando las proposiciones se refieren a cosas reales, con existencia en la realidad, las llama aprehensión real (Newman, 1960). Finalmente, agrega que siempre una aprehensión real será más fuerte que una nocional, en el sentido de que es: "más fuerte, más vivida, más penetrante" (Newman, 1960), porque se refiere a una experiencia de algo concreto.

Por otra parte, por asentimiento entiende: "la aceptación absoluta y sin condiciones de una proposición" (Newman, 1960). El asentimiento requiere de la previa aprehensión, que es la que otorga sentido a los términos. Por lo que, a su vez, puede originar un asentimiento de tipo real o de tipo nocional, según sea la aprehensión que lo origina.

El asentimiento es más que la aprehensión, no solo requiere de un acto mental, sino que además involucra la voluntad y la imaginación. Es decir, es más rico. De aquí la importancia que da Newman a la experiencia, ésta supera la pura abstracción aportando imágenes que hacen más vivo el proceso de asentimiento (Newman, 1960).

\subsubsection{Asentimiento nocional y real}

Ya se ha señalado algo de esto, cuando Newman afirma que un asentimiento real es más fuerte que uno nocional, porque lo concreto tiene una fuerza que deja una 
impresión en las facultades humanas, las cosas que constituyen el objeto de la aprehensión real son más impresionantes y estimulantes que las de la aprehensión nocional.

Para clarificar el hecho de que existan grados en el asentimiento y la distinción entre nocional y real, introduce Newman otro elemento. Se trata del concepto de inferencia. Dice Newman que cuando se da un asentimiento a una noción: "se puede dudar si se trata de un asentimiento o de una inferencia, de si la mente está únicamente en un estado en el que duda, o si realmente tiene certeza" (Newman, 1960). Es decir, lo que ocurre es que el asentimiento nocional se parece a la inferencia, ya que la aprehensión de los actos de inferencia se ocupa generalmente de proposiciones nocionales. De este modo, para Newman, la inferencia normalmente tiene como contenido la aprehensión de proposiciones nocionales (Newman, 1960).

Además, en esta etapa de su reflexión establece otra importante diferencia entre el proceso de inferencia y asentimiento. El asentimiento parece ser más perfecto cuando se ejercita acerca de proposiciones aprehendidas por experiencia, es decir, por imágenes que representan cosas concretas. En cambio, el acto de inferencia, parece más perfecto cuando se ejercita con proposiciones de aprehensiones nocionales. Así, un asentimiento que se basa solo en nociones tiende a convertirse en pura afirmación sin mucha involucración personal (Newman, 1960).

Dentro del asentimiento de tipo nocional distingue Newman cuatro formas (Newman, 1960):

- La creencia: es el tipo de asentimiento que damos a aquellas opiniones y hechos aceptados que continuamente se presentan y que se dan por supuestos.

- La presunción: es el asentimiento de los primeros principios, de las proposiciones con las que empezamos nuestro razonamiento sobre cualquier asunto.

- La especulación: es la contemplación de objetos mentales.

- La opinión: es el asentimiento a una proposición no como verdadera, sino como probablemente verdadera.

Ahora bien, en el asentimiento real la mente no está dirigida a contemplar sus propias creaciones, sino al contrario, está dirigida a contemplar las cosas representadas por las impresiones que han dejado en la imaginación (Newman, 1960). En esto hay que tener en cuenta, según Newman, tres aspectos: 
- La claridad de las imágenes que se requieren para el asentimiento real no son garantía de la existencia de los objetos que representan (Newman, 1960).

- $\quad$ Por fuerte que sea el asentimiento y por vividas que sean las imágenes a las que va ligado, no es por ello necesariamente práctico. Ya que no es la imaginación la que origina la acción, sino la esperanza, el temor, los gustos, las repugnancias, etc. Por ello, aceptar una proposición no garantiza absolutamente que ésta se llevará a cabo (Newman, 1960).

- $\quad$ El asentimiento real es de naturaleza personal, es decir, cada individuo tiene los suyos, no ocurre lo mismo con el asentimiento nocional que es más bien propio de la naturaleza común (Newman, 1960).

\subsubsection{El asentimiento religioso}

Para Newman un dogma de fe es una proposición que puede representar o una noción o una cosa. Y distingue entre acto de religión y de teología. Cuando se da un asentimiento real a una proposición dogmática es un acto de religión, en cambio, cuando se da un asentimiento nocional estaríamos en un acto teológico (Newman, 1960).

En concreto Newman pretende en este apartado investigar "qué es creer", qué implican las proposiciones de la fe (por ejemplo: aborda la creencia en un solo Dios, en la Santísima Trinidad y el desarrollo de la teología dogmática), qué es lo que hace la mente cuando realiza un acto de fe y, como consecuencia de ello, también mostrar porque creemos (Newman, 1960). Se pregunta Newman si es posible una aprehensión real y, por ende, tener un asentimiento real de Dios. Piensa que sí. Para mostrarlo se vale del tema de la conciencia.

El sentido moral es el aspecto más próximo a la dimensión intelectual. Quien discierne emite un juicio sobre la cualidad moral de las acciones concretas. Una acción suscita en nosotros sentimientos dolor, alegría, aprobación o rechazo, que a su vez van configurando una imagen de un divino juez y soberano, es decir, de Dios. La conciencia tiene una función crítica y una judicial, más que una regla de deber, de buena conducta, la conciencia es una sanción sobre las acciones. Recogemos una cita textual que aclara su visión sobre este asunto:

“...la imagen de Dios debidamente cultivada puede extenderse, profundizarse, completarse con el crecimiento de nuestras facultades en el decurso de la vida, bajo la influencia de las variadas lecciones de fuera y de dentro que se nos 
presentan acerca de este Dios uno y personal, por medio de la educación, el trato social, la experiencia y la literatura. Para una mente tan cuidadosamente formada sobre la base de su conciencia natural, el mundo tanto de la naturaleza como del hombre no es sino reflejo de las verdades sobre el Dios viviente, que le han sido familiares desde su niñez." (Newman, 1960)

Lo interesante es que Newman considera esta forma viva de aprehensión de los asuntos religiosos (existencia de Dios), como independientes de la revelación escrita (sobrenatural). Por otra parte, también se refiere en este punto a que no existe una contradicción u antagonismo entre una religión vital y una de corte dogmática ${ }^{8}$. De esta manera, por medio de la conciencia que se va educando, puede el hombre no solo tener un asentimiento nocional, sino también imaginativo y real de que hay un Dios. Pero ¿Ocurre lo mismo con el dogma de la Santísima Trinidad, no parece más bien una afirmación de tipo nocional?, ¿Puede ser mantenida en la imaginación y abrazada con asentimiento real?

Newman reconoce la dificultad de este paso, ya que si se analiza cada uno de sus términos hay que reconocer su complejidad. Ninguna palabra humana parece digna del Ser Supremo para expresarlo; sin embargo, no se pueden usar otras palabras, sino las inteligibles para el lenguaje. Por ejemplo, señala Newman que se habla de la Santísima Trinidad como "misterio", que como tal parece que sólo permitiría un asentimiento nocional. Sin embargo, Newman reclama que el objeto de la aprehensión real o religiosa, no es el misterio en su totalidad, sino el número completo de sus proposiciones una a una. (Newman, 1960) Así consideradas, se puede ir más allá de un asentimiento puramente nocional del misterio

8 La explicación la recojo a pie de página para no desviarnos del tema central. “Muchos insisten en que la salvación está, no en creer las proposiciones de que hay un solo Dios, un salvador, la Santísima Trinidad, sino creer en Dios, en el redentor, en el santificador. Nos objetan que tales proposiciones no son más que un medio formal y humano que destruye toda verdadera aceptación del Evangelio y que convierte la religión en cosa de palabras o de lógica en vez de plantarla al corazón ... las proposiciones pueden y deben ser usadas como expresión de hechos, no de nociones y son tan necesarias a la mente como lo es el lenguaje para denotar hechos ... además las proposiciones son útiles también en su aspecto dogmático para determinar y precisar las verdades en las que la imaginación religiosa debe descansar ... La teología podría quedar como una ciencia sustantiva sin la vida de la religión, pero la religión no podría mantenerse en pie sin apoyarse en el entendimiento... de esta forma toda religión se apoya en el dogma", $A R$, 128-129. 
y podemos imaginar las proposiciones por separado ${ }^{9}$, pero no todas a la vez, porque el misterio trasciende todas nuestras experiencias.

\subsubsection{El asentimiento y la inferencia}

Newman en la segunda parte de la obra que nos ocupa, pasa a profundizar la relación y diferencia entre asentimiento e inferencia. La inferencia es un antecedente del asentimiento y de ordinario un asentimiento va precedido por una inferencia, pero esto no es siempre así ni necesario. Por tanto, asentir no es inferir ni viceversa. Ya se había mencionado que una de sus diferencias importantes está en el hecho de que la inferencia tiene un carácter condicional, en cambio, el asentimiento uno incondicional. En esta diferencia y de la relación entre ambas, surge una dificultad que podemos expresar en forma de pregunta: ¿Cómo puede ser que la aceptación condicional de una proposición (inferencia) pueda llevar a la aceptación incondicional de la misma en el asentimiento? (Newman, 1960)

El asentimiento es relativamente independiente de la inferencia. La inferencia condiciona el asentimiento pero no lo determina, por ejemplo se dan los casos siguientes:

- Hay asentimientos que perduran aún cuando ya no están presente los actos de inferencia que los provocan (Newman, 1960).

- Hay asentimientos que fallan aún cuando perduren las razones que nos llevan a él (Newman, 1960).

- Hay asentimientos que no llegan a producirse a pesar de la presencia de argumentos convincentes (Newman, 1960).

- Hay también asentimientos que se dan aún cuando no existan razones suficientes para ello (Newman, 1960).

Por tanto, hay muchos factores que influyen en el proceso del asentimiento, como por ejemplo, la misma voluntad que da paso a la relación siempre recurrente entre verdad y libertad.

9 Newman habla de 9 proposiciones: "1. Son tres los que dan testimonio en el cielo, el Padre, el Verbo y el Espíritu Santo. 2. Procedente del Padre es y ha sido siempre el Hijo. 3. Procedente del Padre y del Hijo es y ha sido siempre el Espíritu Santo. 4. El Padre es el Dios uno, eterno y personal. 5. El Hijo es el Dios uno, eterno y personal. 6. El Espíritu Santo es el Dios uno, eterno y personal. 7. El Padre no es el Hijo. 8. El Hijo no es el Espíritu Santo. 9. El Espíritu Santo no es el Padre." $A R, 139-140$. 


\subsubsection{La certeza}

Dicho esto, Newman pasa a ocuparse del problema del paso del asentimiento a la certeza. Para él la certeza no coincide propiamente con la mera conciencia de saber, sino que sería propiamente la conciencia fundamentada de saber, para que no se trate de meros prejuicios o falsas creencias. La certeza es el conocimiento de una verdad. Sin embargo, la certeza sería siempre un asentimiento de tipo nocional, ya que asentimos a la verdad de una proposición y para ello actualizamos el proceso inferencial que está en su base.

Certeza y asentimiento tampoco son la misma cosa. Aún cuando, por lo general, las personas no hagan la distinción o ni siquiera se pregunten por ello.

La certeza tiene como objeto la verdad, es decir, una proposición verdadera. Y en este sentido las certezas no deberían cambiar. Pero ¿Se cumplen alguna vez las condiciones que evidentemente se requieren para un estado de certeza? (Newman, 1960) Para Newman es un hecho que las personas cambian sus certezas. Y esto podría llevar a quien las cambia o a quien se da cuenta que estaba en un error a pensar que siempre le ocurrirá lo mismo. Sin embargo, la actitud correcta debe ser tomarlos como avisos para que se raciocine con mayor precaución (Newman, 1960).

No es tarea fácil encontrar un criterio inmediato e interno de la verdadera certeza. Incluso para Newman resulta imposible, porque cuando se dice "yo sé" se condensa en esa expresión toda una serie de juicios que podrían cada uno por separado y sucesivamente, ejercer una función crítica respecto de los que los preceden. Sin embargo, sería una regla general el hecho de que la certeza es indefectible. Constituyéndose éste en un criterio negativo de la certeza o cómo condición para que se de la certeza (Newman, 1960).

Newman agrega tres condiciones requeridas para que haya certeza: que siga a la investigación y a la prueba, que vaya acompañada de un sentido específico de satisfacción y de reposo, y que sea irreversible. Sin esto todo juicio sería temerario o un prejuicio (Newman, 1960).

\subsubsection{El sentido ilativo}

Para Newman la certeza no es una impresión que la mente recibe pasivamente desde fuera y en virtud de un argumento que nos impresiona, sino que es más bien un reconocimiento activo de que las proposiciones son verdaderas (Newman, 1960). Ahora bien, a la facultad de la mente que reconoce la verdad de una 
proposición o la validez de una inferencia, la llama sentido ilativo. Leamos sus propias palabras: "A este poder de juzgar acerca de la verdad y del error en materias concretas lo llamo yo sentido ilativo" (Newman, 1960) Y más adelante agrega: "El sentido ilativo consiste en la capacidad de penetrar con rectitud instintiva en los principios, doctrinas y hechos, ya sean falsos ya verdaderos, y para discernir con presteza que conclusiones son necesarias, convenientes si aquéllos se dan por supuestos" (Newman, 1960).

\subsubsection{La inferencia religiosa}

Newman al hablar de la relación entre asentimiento y aprehensión mostraba, cómo se puede asentir a realidades que no es posible aprehender realmente, como por ejemplo, la Trinidad. En esta etapa de su obra referida a la inferencia religiosa, pretende dar las razones que tenemos para asentir a estas realidades. En este punto es donde vuelve a reivindicar la importancia de la propia experiencia:

"En lo que toca a la investigación religiosa, cada uno de nosotros puede hablar por sí mismo, y tiene derecho a hablar sólo en lo que se refiere a sí. A él le bastan sus propias experiencias, pero no puede pretender hablar para los demás si le satisface a él es posible que le satisfaga a los demás; si, cómo el cree, es verdad, recibirá también la aprobación de los otros, porque no hay más que una sola verdad [...]" (Newman, 1960).

Por ello, lo importante no es tanto la demostración basada en unas razones empírico-científicas que no aparecen en el caso de la religión. Sino más bien, mostrar las razones personales para creer. En este sentido Newman muestra los motivos de su fe, pero no de manera demostrativa, sino por un camino intermedio que sigue un método informal.

1. En primer lugar, aborda lo que entiende por religión (natural). Nos dice: "Por religión entiendo el conocimiento de Dios, de su voluntad y de nuestros deberes con El" (Newman, 1960). Ahora bien, muy interesante resulta la propuesta de Newman de que existen tres canales proporcionados por la naturaleza para adquirir el conocimiento de Dios:

- Nuestra propia mente.

- La voz de la humanidad.

- $\quad$ El curso del mundo. (Newman, 1960)

Nos referiremos brevemente a la primera de ellas. La conciencia es el gran maestro íntimo de religión. Por medio de la conciencia moral percibo la regla del 
bien y del mal y asocio a ellas las intimaciones de un ser trascendente e inmanente a mi mismo que es quien me las provoca. La conciencia no solo enseña que Dios existe, sino también cual es su naturaleza e incluso proporciona a la mente una imagen real de Dios como medio para la adoración. De este modo, la justicia (Dios juez) sería el atributo principal de Dios que presenta la mente-conciencia (Newman, 1960). A éste se asocia la universal imagen del sentido del pecado humano y la institución del sacerdocio, como asimismo, la necesidad de la expiación y del sufrimiento personal (Newman, 1960).

Newman es conciente de que esta imagen de la religión que presenta es su lado más tétrico (como ya lo denunciaba Lucrecio). Sin embargo, lo matiza diciendo que lo hace debido a que dadas las circunstancias de la naturaleza humana y no por culpa de la religión, ésta es la que más resalta. Por otra parte, señala que la religión es siempre una bendición. Aspecto que queda manifestado en el alivio que trae a la angustia de la vida, en las bendiciones y esperanzas religiosas, como asimismo, en la oración.

Finalmente, hay que destacar que para Newman estas creencias y sentimientos naturales son verdaderos y divinos, y pueden llegar a nosotros independientemente de la revelación, incluso pueden actuar como una preparación a ella. (Newman, 1960)

2. En lo referente a la religión en cuanto revelada, Newman señala que el modo de proceder para la posible fundamentación de la verdad de la religión católica, se debería basar en la acumulación de diversas probabilidades (Newman, 1960), o probabilidades convergentes. Y, por otra parte, en que las verdades de la revelación están en cierta relación con las verdades naturales: "es más exacto decir que la creencia en las verdades reveladas depende de la creencia en las verdades naturales" (Newman, 1960). En todo caso, toda posible prueba que se de a favor de la verdad cristiana supone la fe en Dios y la percepción de su presencia, como también, el reconocimiento de sus atributos y su admiración. A partir de esto, es posible abrirse a la revelación y constituirse en su preparación.

De entre los aspectos que Newman resalta de la religión natural en cuantopreparación a la revelación y a su vez como una novedad de su método, encontramos:

El hecho de que la religión natural crea una expectación de que se dará una revelación (Newman, 1960).

No necesariamente los argumentos a favor del cristianismo se deben basar en su carácter milagroso (contra Paley), ya que toda supuesta revelación (otras religiones) también se basan en este argumento (Newman, 1960). 
El cristianismo tiene algo claro que comunicar al hombre y es el que mejor tiende a cumplir las aspiraciones y esperanzas naturales de los hombres. (Newman, 1960)

La singularidad del pueblo hebreo es que muestra una presencia sobrenatural; por su historia, por su fe, por su testimonio. De su seno nace el cristianismo como cumplimiento de las profecías y heredero legítimo de la religión judía (Newman, 1960).

Si bien es cierto que hasta aquí se ha podido ver una cierta relación de continuidad entre la religión natural y la revelación, ya al final de su obra Newman se ocupa de su discontinuidad. La revelación empieza donde acaba la religión natural (Newman, 1960). El cristianismo es el cumplimiento de las promesas hechas a Abraham y de las revelaciones mosaicas, pero también es el único que saca a la religión natural de la impotencia y culpabilidad con que deja al hombre. Por ello, el cristianismo no conoció barreras de ningún tipo para su extensión y, por lo mismo, es siempre joven y jamás un objeto de arqueología.

\section{Comentarios finales}

Para finalizar, se hace referencia a algunos puntos que llaman poderosamente la atención y que poseen hoy mucha vigencia.

a. En primer lugar, una palabra sobre la personalidad del autor. Se considera a Newman como un honesto buscador de la verdad, un hombre libre que sigue la voz de su conciencia como lugar de encuentro de la voluntad Dios. Su búsqueda sincera de la verdad le permite afrontar todas las dificultades que la fidelidad a sus convicciones le provoca. Con razón se le propone como un modelo a seguir para el diálogo ecuménico e interreligioso. Newman, establece como base del diálogo la búsqueda de la verdad y la virtud de la honestidad, teniendo presente que siempre el otro tiene algo importante que decir y de lo cual se puede aprender. Además, destaca su método teológico, siempre fiel a la revelación.

b. En segundo lugar, se destaca el hecho de que en una época cargada de racionalismo, propone la superación de un reduccionismo epistemológico, mostrando cómo la complejidad de la vida humana invita a considerar otras formas de aproximación a la verdad no menos razonables que la empírica o lógico-matemática. Parece interesante volver a la concepción integradora de este autor y salvar así la riqueza de la realidad humana y su vocación de búsqueda de la "verdad", basada en su misma constitución antropológica. Como asimismo, en 
el equilibrio que su pensamiento logra en la relación fe y razón, que le permite asentar la razonabilidad de la fe en una certeza cuyo fundamento es siempre la autocomunicación y autodonación de Dios.

c. Un tercer aspecto y relacionado con lo anterior, se refiere al hecho de que Newman advierte sobre la necesidad de enfrentar el tema de Dios y de la certeza cristiana desde un punto de vista adecuado a la naturaleza del hombre. En este sentido se muestra como un gran conocedor del ser humano, por ejemplo, cuando hace una reivindicación de la importancia de la experiencia, de la imaginación y de los sentimientos a la hora de asentir. No basta solo con un conocimiento abstracto-nocional de Dios, la religión involucra a la vida y al hombre entero. Es necesario abrirse a una perspectiva más existencial de la fe. En este sentido, la propia Iglesia tiene que estar siempre atenta de no caer en un discurso intelectualista y cosificado de Dios y la fe. Se hace necesario cuidar los otros elementos que están involucrados en el proceso de la fe. En este sentido un camino fecundo está siendo la "via pulchritudinis" y las categorías de "encuentro" y "comunión".

d. Finalmente, hay en esta obra de Newman un aporte que puede tender puentes de diálogo y trabajo conjunto entre la teología y las demás áreas del saber. Newman presenta una verdadera "teoría del conocimiento", es decir, del modo en que el hombre puede acceder al conocimiento de Dios que abre posibilidades para la interdisciplinariedad. Es realista, pero a la vez toma en serio la experiencia personal y la subjetividad; presenta una fe razonable, pero fundamentada en lo sobrenatural; muestra una fe personal, pero no individualista.

\section{Referencias}

Benedicto XVI. (2010). Homilía con motivo de su beatificación. En: http://www.vatican.va/ holy_father/benedict_xvi/homilies/2010/documents/hf_ben-xvi_hom_20100919_ beatif-newman_sp.html. Recuperado: el 7 de abril de 2014 desde: www.vatican. va [En línea].

Cabrera, F. (2001). La otra racionalidad: El conocimiento real en la obra de J. H. Newman. Salamanca: p. 10.

Jiménez, A. (1991), "De la apologética clásica a la teología fundamental. La presencia de John Henry Newman", Diálogo Ecuménico. n 86. pp. 183-202.

Montes, G. (1991). Trayectoria teológica de Newman. Hacia la Iglesia Católica. Aproximación biográfica y tarea ecuménica. Diálogo Ecuménico. n 86. pp. 61-78. 
Newman, J. H. (1960), Essay in aid of a grammar of assent (1870). Se usa la versión en español: El Asentimiento Religioso. Ensayo sobre los motivos racionales de la fe. Barcelona: Herder.

Pelà, G. (1991). "Newman y el desarrollo de la teología que inspiró al Vaticano II", Diálogo Ecuménico. $n^{\circ}$ 86. pp. 171-182.

Torres, A. (1991). John Henry Newman: Fe y Razón en una época de crisis. Revista Española de Teología. $n^{\circ}$ 51.pp. 5-42. 